\title{
Patrones de movilidad residencial en la Ciudad de México como evidencia de co-localización de población y empleos
}

ManUEL SUÁREZ-LASTRA. Instituto de Geografía, Universidad Nacional Autónoma de México.

Ja VIER DELGADO-CAMPOS. Instituto de Geografía, Universidad Nacional Autónoma de México.

RESUMEN | El artículo describe la movilidad residencial en la Ciudad de México y encuentra evidencias de un proceso de co-localización entre empleos y vivienda. La metodología empleada se basa en una serie de análisis estadísticos que incluyen una regresión log-log de flujos residenciales entre municipios; y un modelo logístico binomial que predice la probabilidad de cambio residencial, cuando hay cambios en el lugar de trabajo. Concluimos que junto a las características socioeconómicas de las personas que cambian de residencia, existe una clara influencia del lugar de trabajo sobre la elección del lugar de vivienda, que hace de la movilidad residencial un mecanismo social de equilibrio de la estructura urbana.

PALABRAS CLAVE | Movilidad, estructura urbana, distribución espacial, localización, mercado de trabajo.

ABSTRACT | The article describes residential mobility in Mexico City and finds evidence of a co-location process between jobs and housing. The methodology employed is based on a series of statistical analyses including a log-log regression of residential mobility flows between municipalities, as well as a binomial logistic model that predicts the probability of changing residence with given changes of job location. We conclude that together with the socioeconomic characteristics of residents that move, there is a clear influence of the place of work on the choice of housing location. We conclude that residential mobility can be seen as a social equilibrium mechanism that acts as a response to changes in urban structure.

KEY WORDS | Mobility, urban structure, spatial distribution, labour market.

Este artículo forma parte del proyecto SEMARNAT-CONACYT 23496 "Estudio de la calidad del aire en la Corona Regional de la Ciudad de México" que se lleva a cabo en el Centro de Ciencias de la Atmósfera y el Instituto de Geografía Universidad Nacional Autónoma de México.

Recibido el 15 de junio de 2009, aprobado el 9 de noviembre de 2009.

Correspondencia: E-mail: msuarez@igg.unam.mx | elmanix@gmail.com | (52)(55) 56224333 ext. 44832 


\section{Introducción}

La ciudad es uno de los artefactos culturales más fascinantes que ha existido. Gracias a lo cual nos es permitido verla como "artefacto" (estructura, función, causalidad). Distintas sociedades han podido enfrentar las contingencias del medio físico, concentrar un gran número de personas en el mismo espacio y resolver, técnicamente, la concentración misma. Pensar que ese artefacto peculiar sea "cultural" (mediaciones sociales, contingencia, diversidad), nos permite diferenciarlo de la construcción que los castores hacen de sus presas o las abejas de sus panales, y así encuadrar una gama muy amplia de procesos sociales, posibles únicamente en un contexto urbano.

Sin embargo, todavía no sabemos bien cómo se forma la estructura urbana de nuestras ciudades y tampoco si es factible que ésta evolucione, hacia qué y de qué forma. Los primeros modelos, en la acepción de artefacto, esbozaron dos formas de ver la estructura urbana que, desde entonces, ocupan el centro de la discusión. Las ciudades empiezan con, y mantienen por largo tiempo, una estructura monocéntrica. En algún momento de su historia, algunas de ellas desarrollan una estructura policéntrica.

Aunque la transición entre esas dos estructuras se basa en un argumento teórico de eficiencia, no tenemos pruebas empíricas suficientes de que ello sea cierto. El debate yace en si el surgimiento de subcentros económicos permite reducir o no los tiempos de traslado. Un lado del debate sostiene que los subcentros aumentan la eficiencia, ya que acercan los empleos y servicios a los residentes de la ciudad. El otro lado del debate sostiene que la suburbanización del empleo reduce la eficiencia, debido a la generación de viajes cruzados (cross-commuting) entre extremos de la ciudad al alejar a los empleos del centro.

Sea o no, finalmente, más eficiente la suburbanización del empleo que su concentración en el centro, los cambios en la eficiencia (o ineficiencia) de la estructura urbana dependen de la capacidad de co-localización entre empleos y viviendas. Es decir, que los empleos (adecuados) se acerquen a las personas (adecuadas) y/o viceversa con el paso del tiempo. Ligado a este proceso está, necesariamente, el de movilidad residencial o migración intraurbana.

El propósito del presente artículo es describir el proceso de movilidad residencial, y buscar la existencia de vínculos entre ese proceso y el de co-localización de empleos y vivienda. La investigación se presenta mediante análisis estadísticos utilizando fuentes de datos públicas, así como una encuesta propia de movilidad residencial.

Los análisis incluyen una caracterización general del proceso de movilidad residencial, en la que se describen la magnitud, perfil social y motivos de migración intraurbana, mediante estadísticas descriptivas, tablas de continencia y comparaciones de promedios. Asimismo, se determinan los pares municipales con flujos residenciales sobresalientes. Para analizar el proceso de co-localización se realizan dos análisis de regresión que exploran las dos direcciones causales del proceso. El primero es un modelo $\log$-log, que sugiere una relación entre el número viajes al trabajo en un periodo previo y los movimientos residenciales entre pares municipales en un periodo posterior. El segundo es una regresión logística que muestra el incremento en la probabilidad de cambiar de lugar de trabajo cuando el cambio de residencia implica un alejamiento irracional del lugar de trabajo anterior.

A partir de estos análisis se concluye que, además de las características socioeconómicas de las personas y hogares que influyen en el cambio residencial, existe una clara relación 
entre el lugar de trabajo y el de residencia. Asimismo, que los análisis presentados sugieren evidencias de procesos de co-localización entre empleos y vivienda que hacen de la movilidad residencial un mecanismo social de equilibrio de la estructura urbana, sin que esto signifique la "producción" de una estructura policéntrica, en el sentido de artefacto.

El resto del artículo se divide en ocho secciones. Primeramente, se revisa someramente la teoría y las principales aportaciones de la investigación sobre movilidad residencial en México y algunos países de Latinoamérica. En segundo lugar realizamos una breve descripción de la Ciudad de México y presentamos una selección de estadísticas socioeconómicas básicas, utilizando el esquema de contornos urbanos. Luego, describimos las fuentes de datos empleadas. En las secciones cuatro a siete se presentan los análisis realizados. Por la cantidad y complejidad de los análisis realizados se describen los métodos empleados dentro de cada uno de los apartados en lugar de hacer una sección metodológica única. Finalmente, se presentan una serie de conclusiones y recomendaciones de política pública.

\section{Teoría y estudios previos}

Buena parte de la discusión sobre movilidad residencial está enmarcada en la relación entre el uso de suelo y el transporte y la influencia de la ubicación de las fuentes de empleo sobre las decisiones de localización residencial. En el modelo monocéntrico, las decisiones de localización se toman en función de la distancia al centro de la ciudad, en donde se encuentra la mayor parte del empleo. Cada sujeto elige vivir tan cerca del centro como pueda pagar por ello. Mientras más personas estén dispuestas a pagar el costo de la centralidad, las densidades aumentarán (Alonso, 1964; Muth, 1969; Mills, 1972).

Es difícil pensar que las grandes ciudades modernas puedan mantener, indefinidamente, un esquema monocéntrico. Para el caso de la Ciudad de México, existen distintas opiniones sobre su eventual grado de policentrismo (Graizbord y Acuña, 2005; Aguilar y Alvarado, 2005; Graizbord, 2008; Suárez y Delgado, 2009). Aún así, es probable que los supuestos clásicos de economía urbana de la ciudad monocéntrica sean todavía válidos. La diferencia, es que para el caso de la ciudad policéntrica, los gradientes del precio del suelo, del costo de transporte, de densidad y mezcla de uso, estarán en función de las distancias a los diferentes subcentros, cada uno de tamaño y características económicas y de transporte distintas (Cervero, 1997; 1998; Fujita, 1999). Incluso Alonso (1964) consideró la posibilidad policéntrica como una forma compleja del modelo monocéntrico.

En este sentido, lo importante es saber si la transición hacia estructuras policéntricas hace más eficiente el funcionamiento de la ciudad. Según Fujita (1999) es precisamente la eficiencia lo que justifica el paso del monocentrismo al policentrismo. Al crecer la ciudad y, cuando la distancia entre sus orillas y el centro sobrepasa un tiempo de traslado "razonable", es posible que surjan subcentros económicos que permitan disminuir los tiempos de traslado ${ }^{1}$. La suburbanización del empleo empieza por la aparición de actividades comerciales locales, que tienen el menor valor agregado y que no requieren de una aglomeración económica para su funcionamiento. Con el tiempo, y a medida que aumenta la suburbanización del empleo, se generan nuevas aglomeraciones que, al llegar a un cierto umbral crítico, se convierten en nuevos subcentros económicos (Chintitz, 1961; Kaldor, 1985; Krugman, 1991; Bogart 1998). 
Ahora bien, la eficiencia que genera el policentrismo está sujeta a debate. Por un lado, Hamilton (1982) demostró que si la ciudad de Los Ángeles fuera completamente monocéntrica, los traslados cotidianos se reducirían hasta por un factor de ocho. Por otro lado, se ha sugerido que las estructuras policéntricas permiten la co-localización de vivienda y empleos (Levinson y Kummar, 1994), es decir, una accesibilidad autogenerada. Lo importante de esta discusión es que, de existir dicha co-localización al interior de la ciudad, este proceso sería necesariamente resultado de la movilidad residencial ${ }^{2}$. Incluso podría sugerirse que las estructuras policéntricas sólo se vuelven eficientes si existe un proceso de co-localización entre empleos y viviendas.

Una revisión de la literatura existente revela que la co-localización puede adoptar dos formas, no necesariamente excluyentes. Una primera es que se elija el lugar de residencia en función del lugar de empleo, como sostiene el modelo clásico. Una segunda forma es que se elija el lugar de trabajo en función del lugar de residencia (Deitz, 1998; Simpson, 1992; Suárez, 2007). Así, entre las diversas formas de estudiar la movilidad residencial intraurbana sobresale el interés en las causas de los movimientos residenciales, en la probabilidad de cambio de residencia, así como en la elección de la localización. Ello se ha hecho mediante modelos de comportamiento, o bien mediante modelos estadísticos.

En los modelos de comportamiento se analiza el proceso de movilidad a nivel del hogar, paso por paso. Los más representativos lo visualizan bajo la forma de flujos de decisiones escalonadas (Brown y Moore, 1970) o como una serie de decisiones simultáneas (Smith et al., 1979). Por su parte, desde una perspectiva económica, la premisa básica de los modelos de comportamiento es que los costos de relocalización condicionan la posibilidad de movilidad de los hogares, es decir, que el consumo de vivienda se ajusta a los cambios en la demanda (Hanushek y Quigley, 1978; Cronin, 1979; Weinberg, Friedman et al., 1981). Dicho de otra forma, un hogar tiene una demanda específica de vivienda en diferentes periodos de tiempo que puede o no equilibrarse de acuerdo con su nivel de ingreso.

En los modelos estadísticos, por su parte, se analizan los movimientos entre orígenes y destinos (Huff y Clark, 1978) y el comportamiento general de la localización (Alonso, 1964; Muth, 1969) vista como efecto y resultado de la estructura urbana. La teoría detrás de estos modelos es la teoría urbana clásica a la que se hizo referencia al inicio de esta sección. Esta última perspectiva es la que se adopta para los análisis que se realizan en este artículo.

Aun con la existencia de diferentes perspectivas y enfoques teórico-metodológicos sobre la movilidad residencial, parecería que en lugar de contraponerse se complementan, y que, por lo tanto, pueden resumirse de la siguiente forma: existe un deseo de movimiento residencial relacionado con la satisfacción de una necesidad. El deseo, necesidad y posibilidad de cambio están en función de una serie de variables socioeconómicas y espaciales. De ello nace una decisión de cambio que desemboca en la elección de localización. El lugar elegido reporta una cierta utilidad a sus usuarios respecto a lo que empujó la decisión de mudarse, pero está sujeto tanto a la disponibilidad de espacio (vacancia) en el lugar de elección como a su capacidad de pago (Figura 1).

En términos de la teoría clásica, pero sin tomar el centro de la ciudad como referencia, existiría pues una localización ideal de cambio residencial que maximiza la utilidad del hogar. La distancia a la que se ubique un hogar, respecto a su localización ideal, estará sujeta al presupuesto para gasto en vivienda (Figura 2). Las características de los hogares que se mudan de residencia, así como los principales resultados y consensos de las investigaciones acerca de ello, se muestran en el Cuadro 1.

2 A nivel regional podría argumentarse que hay un proceso en el que los empleos siguen a la gente con cierta especialización (Krugman, 1991). 
FIGURA 1 | Etapas y perspectivas del proceso de movilidad residencial

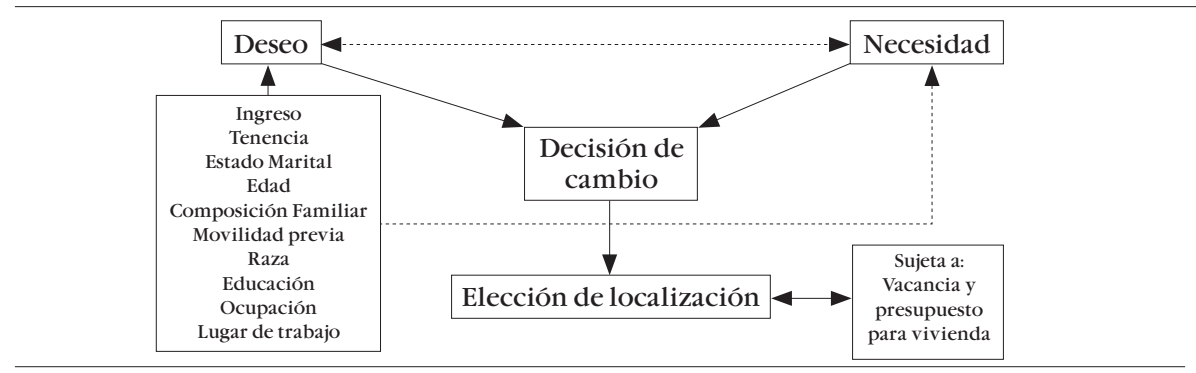

FUENTE ELABORACIÓN PROPIA.

FIGURA 2 | Función de utilidad de elección de localización residencial

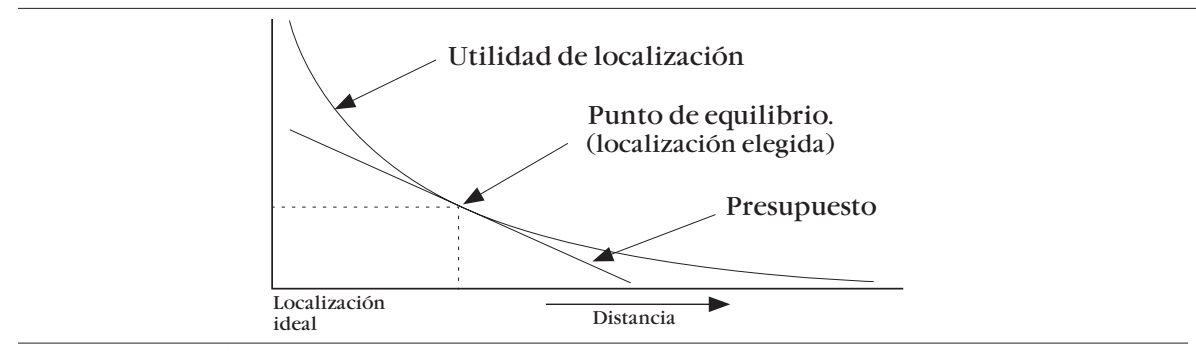

FUENTE ELABORACIÓN PROPIA CON BASE EN FUENTES REVISADAS.

CUADRO 1 | Asociación entre la movilidad y las características del hogar

\begin{tabular}{|c|c|c|}
\hline Factores & Características del hogar & Consensos \\
\hline \multirow{7}{*}{ SOCIALES } & Estado conyugal & $\begin{array}{l}\text { Quienes nunca se han casado son menos móviles } \\
\text { Divorciados y separados muestran mayor movilidad } \\
\text { Cambios en el estado marital aumentan la movilidad }\end{array}$ \\
\hline & Edad del jefe de familia & La movilidad disminuye con la edad \\
\hline & Sexo del jefe de familia & Evidencia mixta \\
\hline & Tamaño del hogar & $\begin{array}{l}\text { Evidencia mixta } \\
\text { Cambios en el tamaño del hogar están altamente correlacionados } \\
\text { con la movilidad }\end{array}$ \\
\hline & Composición del hogar & El número de niños en la escuela reduce la movilidad \\
\hline & Educación & $\begin{array}{l}\text { A mayores niveles de educación, mayores niveles de movilidad, la } \\
\text { evidencia es débil. }\end{array}$ \\
\hline & Raza & Evidencia mixta \\
\hline \multirow{3}{*}{ ECONÓMICOS } & Ingreso & $\begin{array}{l}\text { Cambios en el ingreso están asociados a la movilidad. Los más } \\
\text { altos niveles de movilidad parecen estar asociados a la categoría } \\
\text { de ingreso medio, pero la evidencia es mixta }\end{array}$ \\
\hline & Tenencia & $\begin{array}{l}\text { Quienes rentan muestran mayor movilidad que quienes } \\
\text { compran }\end{array}$ \\
\hline & Ocupación & Evidencia mixta \\
\hline \multirow{2}{*}{ ESPACIALES } & Lugar de trabajo & $\begin{array}{l}\text { Diversos estudios y evidencias contradictorias. No existe un } \\
\text { consenso. }\end{array}$ \\
\hline & Movilidad previa & Movilidad previa esta correlacionada con movilidad actual \\
\hline
\end{tabular}

FUENTE BASADO EN PORRELL (198I) CON ADICIONES DE LOS AUTORES.

Para Latinoamérica, Pinto da Cunha (2002) ha recalcado el número creciente de "procesos de redistribución intrametropolitana" de la población que, según el autor, son cada vez más complejos y de mayor magnitud. Destacan, además, los estudios de Delaunay y Dureau (2004) que explican los componentes de segregación de los procesos de movilidad residencial intraurbana en Bogotá. Asimismo, las diversas perspectivas de 
reconfiguración metropolitana a causa de la movilidad residencial en la ciudad de Santiago de Chile, que se exploran en de Mattos e Hidalgo (2007).

Para la Ciudad de México no existe una tradición analítica sobre el tema. Es apenas en 1995 cuando se levantó el primer conteo intercensal en el país, y que los cambios residenciales intermunicipales se empezaron a explorar. El interés reciente sobre movilidad residencial se ha enfocado en el proceso general, volumen y dirección de flujos, que ha puesto de relieve movimientos importantes de oriente a poniente y desde viviendas más antiguas hacia otras nuevas (Sobrino e Ibarra, 2003; Graizbord y Acuña, 2007). También se ha sugerido una relación entre la movilidad residencial y procesos de segregación espacial desde la publicación del estudio pionero de Rubalcava y Schteingart (1987), presente también en el trabajo de Duhau (2003), quien subraya la importancia del ingreso en el movimiento residencial. Adicionalmente, se ha sugerido que existe una asociación entre el lugar de trabajo y el de residencia (Sobrino e Ibarra, 2005) que podría ser de distinta naturaleza entre grupos de ingresos distintos (Sobrino, 2007; Sobrino e Ibarra, 2008). Finalmente, Cruz y Duhau (2001) encontraron una asociación entre el mercado laboral industrial y las decisiones de cambio residencial hacia un municipio de la periferia de la Ciudad de México.

Hasta ahora, la descripción de los flujos se ha hecho en términos de análisis bivariados, es decir, en donde la movilidad responde a una causa, sin profundizar en el efecto parcial y combinado de otras variables. Por otra parte, la dirección de los flujos se ha presentado de manera agregada y las causas de movilidad por motivo de trabajo se han estudiado a escala local. Tampoco se sabe bien, para la ciudad en su conjunto, si los patrones de cambio residencial entre pares municipales (origen-destino) forman patrones de co-localización entre los empleos y el lugar de vivienda, y si ello puede impulsar una estructura policéntrica.

Así, las preguntas centrales parecen ser: ¿qué tipos de flujos suceden, en qué partes de la ciudad? ¿Cuál es la influencia de la localización de empleos sobre los movimientos residenciales a escala metropolitana? ¿Existen evidencias de co-localización entre empleos y viviendas, ya sea como resultado de la localización del empleo o de la localización de la vivienda? Empecemos por el contexto en donde se producen estos cambios.

\section{La estructura urbana de la ciudad}

Para ubicar la trama de esos flujos partimos por una abstracción espacial de la estructura urbana de la ciudad, basada en el modelo de círculos concéntricos de Burgues. Dicho esquema se basa en una interpretación propia del modelo original, que consiste en definir los distintos contornos en términos del proceso histórico de urbanización de la ciudad, y no únicamente por su contigüidad geográfica (Delgado, 1988). Con frecuencia se confunde la morfología de la ciudad con su dinámica (Suárez y Delgado, 2009). El modelo de círculos se refiere a la dinámica y aunque la aplicación original del modelo se basó, principalmente, en la densidad de población como una función de la distancia al centro, también es útil para visualizar la dinámica del empleo y de los cambios residenciales intraurbanos ${ }^{3}$.

\footnotetext{
3 Desde los años 70, en México, varios autores han utilizado el modelo para analizar el comportamiento de la vivienda, y en particular, de la vivienda en renta, la industrialización, el empleo y la PEA, la estructura de edad, así como para delimitar el área metropolitana. Sin embargo, no existe ninguna sistematización de conjunto, probablemente por el recelo ante una cierta crítica que considera al modelo como una "explicación geométrica" y no una abstracción de su dinámica (Suárez y Delgado, 2009).
} 
La Figura 3 muestra la delimitación de los contornos urbanos. La ciudad central, constituida por las cuatro delegaciones centrales, contiene al centro histórico tradicional y al distrito central de negocios, y desde la primera mitad de los 90 se observa una relativa renovación de su centralidad (Delgado et al., 1997). El primer contorno se formó con las áreas urbanizadas entre 1930 y 1950, todavía dentro del Distrito Federal, y corresponden a la fase económica y política de creación del mercado interno y de instituciones sociales, en educación, salud y abasto, pero muy poco en cuanto a desarrollo urbano. El segundo contorno es resultado de la mayor expansión urbana de la ciudad verificada entre 1950 y 1970, cuando la ciudad se desbordó sobre la entidad vecina que dio pie a una normatividad y burocracia dirigidas a la cuestión urbana. El tercer contorno se formó desde 1970 y, aproximadamente, hasta 1990, durante la vigencia formal de una planeación gubernamental más estricta que, sin embargo, no impidió la ocupación indiscriminada de municipios propiamente rurales, aumentando la complejidad de su estructura socioespacial. El cuarto contorno se está conformando desde entonces, cuando el modelo neoliberal impuesto a nivel federal retiró la intervención del Estado del mercado formal de vivienda y desmanteló lo esencial del aparato de planeación urbana gubernamental.

FIGURA 3 | Contornos metropolitanos

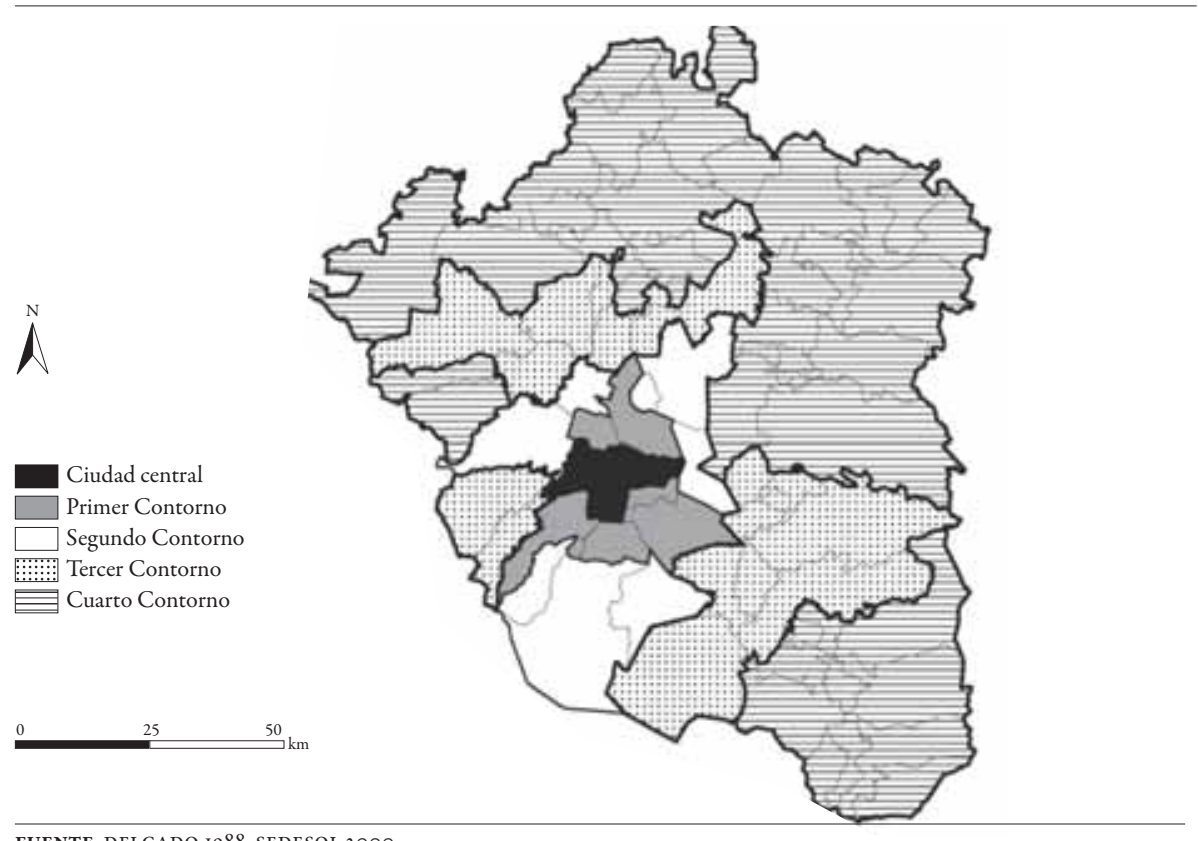

FUENTE DELGADO 1988 , SEDESOL 2000.

El Cuadro 2 muestra algunas características socioeconómicas de los contornos urbanos de la Ciudad de Méxicót. Mientras que la pendiente de la densidad de empleos es una curva logarítmica en función de la distancia al centro, la población ha tomado una forma cuadrática a partir de 1990. Esto se debe, en parte, a una conversión de uso de suelo, de residencial a comercial y de servicios, producto de la concentración de actividades económicas en el centro de la ciudad (Suárez y Delgado, 2007). Así, el suelo urbano cercano al centro sigue siendo el más caro y, quienes viven ahí tienen el ingreso y escolaridad

4 En este texto se utiliza la denominación "Ciudad de México" (que administrativamente se refiere únicamente al Distrito Federal) para referirse a la "Zona Metropolitana de la Ciudad de México", que incluye además a 59 municipios conurbados del vecino Estado de México. 
más altos. Tanto la escolaridad como el ingreso se reducen con la distancia al centro. En cuanto a la migración intraurbana neta, tanto la ciudad central como los contornos uno y dos mostraron tasas negativas y sólo en el tercer y cuarto contornos fueron positivas.

CUADro 2 | Ciudad de México: Estadísticas socioeconómicas, seleccionadas por contorno urbano, 2000

\begin{tabular}{l|c|c|c|c|c|c}
\hline \multicolumn{1}{c|}{ Contorno } & $\begin{array}{c}\text { Población } \\
\text { (millones) }\end{array}$ & $\begin{array}{c}\text { Densidad de } \\
\text { población } \\
\text { (Hab/Ha) }\end{array}$ & $\begin{array}{c}\text { Densidad } \\
\text { de empleos } \\
\text { (Hab/Ha) }\end{array}$ & $\begin{array}{c}\text { Ingreso medio } \\
\text { por trabajo anual } \\
\text { (dólares, EU) }\end{array}$ & $\begin{array}{c}\text { Escolaridad } \\
\text { media, población } \\
\text { ocupada (años) }\end{array}$ & $\begin{array}{c}\text { Migración } \\
\text { intraurbana } \\
\text { neta 1995-2000 } \\
\text { (miles) }\end{array}$ \\
\hline Ciudad central & 1,69 & 124 & 105 & 6.767 & 11,2 & -117 \\
$1^{\text {er }}$ & 5,17 & 138 & 25 & 5.183 & 10,2 & -206 \\
$2^{\text {do }}$ & 5,60 & 114 & 15 & 4.511 & 9,5 & -116 \\
$3^{\text {er }}$ & 4,51 & 68 & 6 & 4.223 & 9,0 & 385 \\
$4^{\text {to }}$ & 1,38 & 32 & 3 & 3.023 & 8,4 & 54 \\
Total & 18,45 & 88 & 17 & 4.799 & 9,7 & 0 \\
\hline
\end{tabular}

a Corresponde a la educación de la población económicamente activa ocupada.

b Resultado de la resta entre los cambios residenciales desde el contorno, restados de los cambios residenciales hacia el contorno.

FUENTE CÁLCULOS DE LOS AUTORES CON BASE EN INEGI 2000, I999.

\section{Fuentes de datos}

Las bases de datos que se utilizan en el estudio están divididas en tres: públicas primarias, públicas complementarias y propias. Las públicas primarias son la base de datos de la muestra del Censo de Población y Vivienda de 2000, la base de datos del Conteo de Población y Vivienda de 1995 y los Censos Económicos de 1989, 1994 y 1999, a nivel municipal. Las públicas complementarias son la Encuesta Origen-Destino de 1994, Encuestas de Ingresos y Gastos de los Hogares de 1994 y 2000 y los tabulados de los censos de población y vivienda 1990 y 2000 a nivel municipal. Estas fuentes se utilizan para complementar la información que no proveen las fuentes primarias. Por último, se utiliza la información de una encuesta propia sobre movilidad residencial que fue levantada en la ZMCM durante los primeros meses de 2003. La encuesta consta de una muestra de 400 casos de jefes de familia que cambiaron de residencia dentro de la zona metropolitana entre 1993 y 2003. Esta encuesta complementa los datos de la base de datos del censo y contiene información socioeconómica de jefes de familia en el lugar de residencia actual y el lugar de residencia anterior, así como motivos de cambio, lugar y tiempo de viaje al trabajo en ambos lugares de residencia.

\section{Caracterización general de la movilidad residencial}

Cambio residencial en la Ciudad de México, 1995-2000: magnitud, perfil socialy causas

Los cambios residenciales intraurbanos significaron una transformación de la urbanización conocida hasta entonces. Si bien el crecimiento poblacional absoluto entre 1990 y 2000 fue de 4.4 millones, para llegar a un total de 18.5 millones de habitantes, el número de viviendas habitadas aumentó más rápido que la población y la emigración duplicó a la inmigración, para alcanzar una migración neta negativa de cerca de un millón de personas.

Eso significa que, durante el periodo, lo fundamental de la dinámica poblacional de la ciudad se debió exclusivamente al crecimiento natural, y la expansión metropolitana se explica, principalmente, por la relocalización de personas y actividades económicas. 
La estructura urbana misma, entendida como conformación socioespacial -o como artefacto cultural, si se quiere-, se transforma e incluso se mantiene, como veremos en este ensayo, gracias a la migración intraurbana.

El número de cambios residenciales intermunicipales al interior de la Ciudad de México involucró a dos de cada 25 habitantes en 1995, cerca de 1.4 millones de personas en total. Una cifra similar se registró entre 1990 y 1995. Si en lugar de contar a la población total se considera a los jefes de familia, la proporción aumenta a uno de cada diez, o alrededor de 344 mil jefes de familia. Si además se toman en cuenta los cambios residenciales intramunicipales, la proporción total de cambios residenciales es, al menos, 25 por ciento más alta que la reportada en el Censo (Cuadro 3).

A partir de los datos de la microbase del Censo de Población de 2000, se sabe que quienes cambiaron de residencia entre 1995 y 2000 tenían más ingreso que los que permanecieron en la misma vivienda, pertenecían a hogares pequeños y eran más jóvenes. Los hogares más ricos se mudaron hacia y desde el centro y los más pobres lo hicieron en la periferia. Los hogares con vivienda en renta, provenientes principalmente del centro, fueron dos veces más móviles que los de viviendas propias. La "preferencia” por los departamentos disminuyó del centro a la periferia y provino de hogares con mayores ingresos, quienes ocuparon viviendas nuevas y con mayores servicios urbanos (Suárez, 2007; ver Cuadro 4).

Las causas que empujaron las transformaciones, en cambio, no son tan claras y los resultados del último censo ayudaron poco a entenderlas. En efecto, a pesar de que se pudieron identificar, como motivos importantes, el reunirse con la familia por haber contraído matrimonio o para buscar o cambiar de trabajo, la opción de "otras causas" superó la mitad de las respuestas (59\%), dejando una gran incertidumbre sobre lo que

CUADro 3 | Ciudad de México: Dinámica poblacional 1995-2000

\begin{tabular}{|c|c|c|}
\hline \multirow{4}{*}{ POBLACIÓN } & Población total 1995 & 17.297 .539 \\
\hline & Población total 2000 & 18.396 .677 \\
\hline & Cambio poblacional & 1.099 .138 \\
\hline & \% Cambio población & $6,4 \%$ \\
\hline \multirow{3}{*}{$\begin{array}{l}\text { CRECIMIENTO } \\
\text { NATURAL }\end{array}$} & Muertes & 411.201 \\
\hline & Nacimientos & 2.061 .461 \\
\hline & Crecimiento natural de población & 1.650 .260 \\
\hline \multirow{3}{*}{$\begin{array}{l}\text { CRECIMIENTO } \\
\text { SOCIAL }\end{array}$} & Migración neta & -551.122 \\
\hline & Inmigración & 566.814 \\
\hline & Emigracion & -1.117 .936 \\
\hline \multirow{8}{*}{$\begin{array}{l}\text { ESTRUCTURA } \\
\text { URBANA }\end{array}$} & Cambios residenciales (Intermunicipales) & 1.435 .034 \\
\hline & Cambios residenciales (Intramunicipales)* & 473.561 \\
\hline & Viviendas habitadas 1995 & 3.905 .143 \\
\hline & Viviendas habitadas 2000 & 4.345 .569 \\
\hline & Cambio viviendas habitadas & 440.426 \\
\hline & \% Cambio viviendas habitadas & $11,3 \%$ \\
\hline & Promedio de ocupantes por vivienda 1995 & 4,4 \\
\hline & Promedio de ocupantes por vivienda 2000 & 4,2 \\
\hline
\end{tabular}

$* \mathrm{p}= \pm 7 \%$ al $95 \%$ de confianza.

FUENTE CÁLCULOS DE LOS AUTORES CON BASE EN: INEGI (2000), INEGI (1995), ESTADÍSTICAS DE NATALIDAD Y MORTALIDAD INEGI (1996, 1997, 1998, 1999, 2000C) Y ENCUESTA PROPIA. 
CUADro 4 | Ciudad de México: Características socioeconómicas y de estructura urbana de la migración intraurbana $(1995-2000)^{a}$

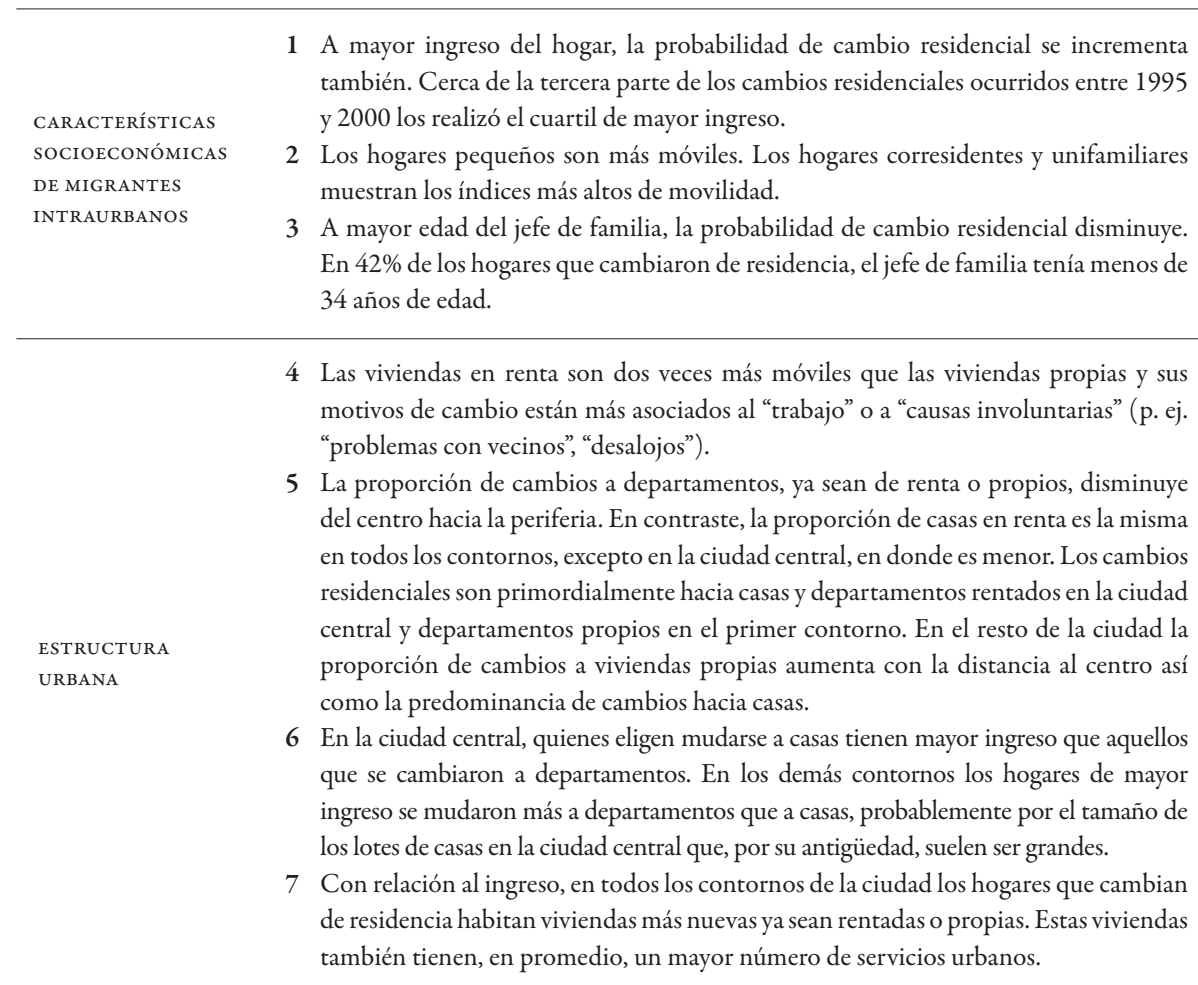

a Todas las relaciones presentadas en este cuadro suponen una significación estadística de al menos 0.05 . FUENTE BASADO EN SUÁREZ, 2007.

CUADro 5 | Ciudad de México: Causas de cambio residencial interestatal 1995-2000

\begin{tabular}{l|c|c}
\hline & Porcentaje Totales & Porcentaje Jefes de Familia \\
\hline Otra causa & $59,2 \%$ & $57,9 \%$ \\
Reunión con familia & $13,3 \%$ & $7,5 \%$ \\
Se casó o unió & $13,1 \%$ & $15,8 \%$ \\
Búsqueda o cambio de trabajo & $8,2 \%$ & $13,1 \%$ \\
Violencia/inseguridad & $3,7 \%$ & $3,5 \%$ \\
Salud & $1,6 \%$ & $1,6 \%$ \\
Fue a estudiar & $1,0 \%$ & $0,4 \%$ \\
Total & $100,0 \%$ & $100,0 \%$ \\
\hline
\end{tabular}

FUENTE CÁLCULOS DE LOS AUTORES A PARTIR DE INEGI, 2000.

encubre esa cifra. Además, la pregunta permite conocer, únicamente, las causas de movimientos entre el Estado de México y el Distrito Federal, mismos que representan 40\% del total de los movimientos residenciales metropolitanos (Cuadro 5).

Es probable que lo abultado del porcentaje en la categoría "otras causas" se deba a la dificultad, para quienes respondieron el censo, de separar las razones para el cambio residencial, claramente distintas para cada miembro de una misma familia. Mientras 
que para el jefe de familia la razón pudo haber sido el "cambio de lugar de trabajo", la conyugue podría haber considerado la de "reunión familiar" y, para los hijos, la "cercanía a la escuela" que no necesariamente se incluye en la categoría "fue a estudiar".

La mayoría de las escasas publicaciones sobre migración intraurbana han enfrentado este problema en la formulación del reactivo censal. Aun así, Sobrino e Ibarra, al comparar las causas de cambio residencial entre inmigrantes (personas provenientes de fuera de la Zona Metropolitana) e inmimetros (personas que cambian de residencia dentro de la ciudad, entre el Estado de México y el Distrito Federal) encontraron que, entre los inmigrantes, la primera causa de cambio residencial era la búsqueda de trabajo, pero que esta razón era menor entre los inmimetros. Para explicar esa diferencia sugirieron que en la fallida categoría de "otras causas" del censo podrían muy bien estar incluidos elementos relacionados con el comportamiento del mercado de suelo y de la vivienda (Sobrino e Ibarra, 2005).

Para superar esta deficiencia se aplicó una encuesta propia a jefes de familia que cambiaron de residencia en la Ciudad de México entre 1993 y 2003, y que permite desagregar el grupo de "otras causas" del Censo. En ella se preguntó, explícitamente, por el motivo de cambio residencial del jefe de familia y distingue entre cambios residenciales interestatales, intermunicipales e intramunicipales. De sus resultados, conviene resaltar la causa de "cercanía al trabajo" $(22,6 \%)$ como segunda causa, más cercana a la primera causa de "compra-venta y renta" (24,6\%), y muy distinta del 8,2\% que le asignó el censo a la "búsqueda o cambio de trabajo". Estos resultados parecen confirmar lo sugerido por Sobrino e Ibarra (2005), acerca del rol del mercado inmobiliario asociado a los cambios de uso de suelo, crecimiento del empleo y la competencia por el espacio en la ciudad (Cuadro 6). Por su parte, en tanto que las codificaciones del Censo y la Encuesta son comparables entre sí, es notoria la similitud entre las proporciones otorgadas a las razones de "matrimonio" y a las de "inseguridad/medio ambiente, violencia/salud".

Es necesario subrayar que las causas de cambio en ningún momento son excluyentes, por lo que un análisis bivariado puede ser limitado. En efecto, quien cambia de residencia para comprar una vivienda podría elegir el sitio en términos de la localización del empleo. Asimismo, alguien que decide vender su residencia podría, al mismo tiempo, elegir la nueva localización de acuerdo con una función de utilidad que incluyera mayor espacio en combinación con la distancia al trabajo. Por esto, es necesario dominar una serie de variables de control.

CUADro 6 | Ciudad de México: Causas de cambio residencial intrametropolitano (jefes de familia) 1993-2003*

$\begin{array}{lr}\text { Compra-venta } & 24,6 \% \\ \text { Cercanía al trabajo o escuela } & 22,6 \% \\ \text { (Incluye cambio de lugar de trabajo) } & \\ \text { Problemas económicos / desalojo } & 16,4 \% \\ \text { Matrimonio/Independencia } & 13,1 \% \\ \text { Problemas personales/vecinos } & 10,2 \% \\ \text { Mejorar la vivienda/Mayor espacio } & 7,9 \% \\ \text { Medio ambiente/Inseguridad } & 5,2 \%\end{array}$

* Contempla sólo los municipios que el INEGI considera como metropolitanos. n=389.

FUENTE ENCUESTA DE LOS AUTORES.

5 Según resultados de la encuesta propia, con intervalo de confianza de $=0.32 \pm 7 \%$, al $95 \%$. Donde: $=$ Proporción media de cambios residenciales que ocurren dentro del mismo municipio de vivienda anterior, no considerados en la base de datos del censo (Suárez, 2007). 
Ahora veremos si se puede ponderar la dinámica general de los movimientos residenciales entre contornos.

\section{Movimientos entre contornos metropolitanos}

Desde el punto de vista del origen principal de los destinos por contorno, se observa un claro patrón de movimientos centro-periferia, así como una serie de cambios dentro del mismo contorno. El principal origen de los cambios hacia la ciudad central (CC) proviene del primer contorno (1C, $41 \%)$, al primero desde el primero (32\%), y segundo (2C, 29\%), al segundo desde el primero (46\%), al tercero (3C) desde el segundo (39\%) y al cuarto (4C), también desde el segundo (ver Cuadro 7 y Figura 4 ).

FIGURA 4 | Principales cambios residenciales entre contornos 1995-2000

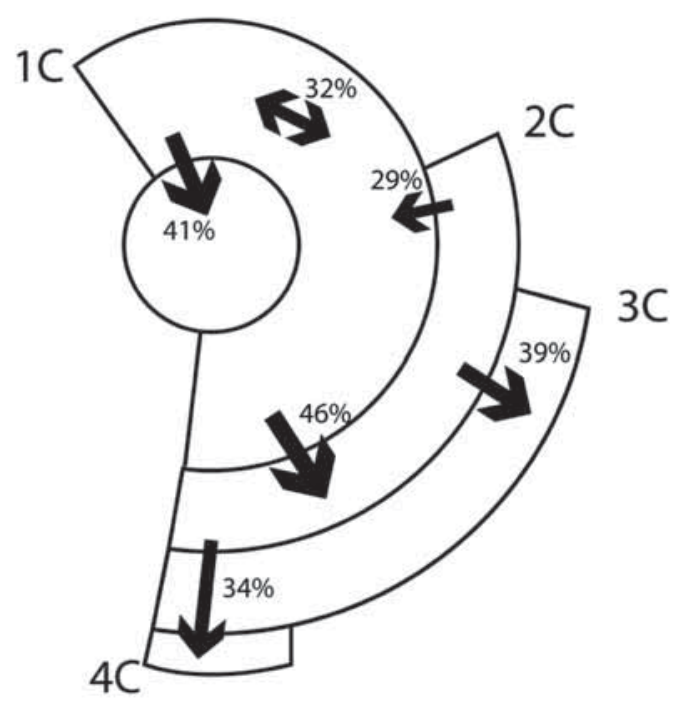

FUENTE ELABORACIÓN PROPIA.

Esto significa que sólo seis flujos principales absorbieron $44.8 \%$ del total, siendo las áreas del 1C y 2C las más dinámicas. Estos anillos se formaron a lo largo de 40 años (1930-1970), cuando al conurbarse con municipios mexiquenses la ciudad central dio paso, técnicamente, a la formación de un área metropolitana. Hoy constituyen -después de la ciudad central- lo principal de la estructura urbana de la ciudad. En términos de planeación, se suspendió la prohibición de fraccionamientos en el DF, lo que desató la oleada especulativa en el vecino Estado de México, junto con la construcción de suburbios para la clase media y alta. Además, se iniciaba la construcción del Metro y del Periférico, cuando la operación de las grandes instituciones públicas de vivienda llegaba a su fin (Schteingart y Graizbord, 1998).

Sin embargo, las posibilidades de combinación origen-destino son mucho más complejas. En el Cuadro 7 se muestra el volumen y porcentajes de flujos entre contornos metropolitanos. Observando el destino de los movimientos por contorno de origen, el tercer contorno recibe la mayor parte de los movimientos residenciales (40\%) y es el principal destino de los cambios originados en los contornos uno, dos y tres, así como 
CUADRo 7 | Ciudad de México: Volumen y porcentajes de movimientos residenciales, 1995-2000

\begin{tabular}{|c|c|c|c|c|c|c|c|c|}
\hline & & & \multicolumn{5}{|c|}{ Contorno Destino 2000} & \multirow{2}{*}{ Total } \\
\hline & & & 0 & 1 & 2 & 3 & 4 & \\
\hline \multirow{15}{*}{$\begin{array}{l}\text { CONTORNO } \\
\text { ORIGEN } \\
1995\end{array}$} & \multirow{3}{*}{0} & Movimientos & 32.345 & 85.144 & 58.180 & 61.475 & 6.298 & 243.442 \\
\hline & & $\%$ Contorno 95 & $13 \%$ & $35 \%$ & $24 \%$ & $25 \%$ & $3 \%$ & $100 \%$ \\
\hline & & $\%$ Contorno 00 & $26 \%$ & $28 \%$ & $18 \%$ & $11 \%$ & $7 \%$ & $17 \%$ \\
\hline & \multirow{3}{*}{1} & Movimientos & 51.277 & 97.196 & 150.534 & 191.860 & 21.402 & 512.269 \\
\hline & & $\%$ Contorno 95 & $10 \%$ & $19 \%$ & $29 \%$ & $38 \%$ & $4 \%$ & $100 \%$ \\
\hline & & $\%$ Contorno 00 & $41 \%$ & $32 \%$ & $46 \%$ & $33 \%$ & $22 \%$ & $36 \%$ \\
\hline & \multirow{3}{*}{2} & Movimientos & 28.778 & 87.423 & 72.639 & 223.243 & 33.267 & 445.350 \\
\hline & & $\%$ Contorno 95 & $7 \%$ & $20 \%$ & $16 \%$ & $50 \%$ & $8 \%$ & $100 \%$ \\
\hline & & $\%$ Contorno 00 & $23 \%$ & $29 \%$ & $22 \%$ & $39 \%$ & $34 \%$ & $31 \%$ \\
\hline & \multirow{3}{*}{3} & Movimientos & 12.237 & 31.932 & 41.395 & 83.782 & 21.112 & 190.458 \\
\hline & & $\%$ Contorno 95 & $6 \%$ & $17 \%$ & $22 \%$ & $44 \%$ & $11 \%$ & $100 \%$ \\
\hline & & $\%$ Contorno 00 & $10 \%$ & $10 \%$ & $13 \%$ & $15 \%$ & $22 \%$ & $13 \%$ \\
\hline & \multirow{3}{*}{4} & Movimientos & 2.016 & 4.618 & 6.523 & 14.807 & 15.551 & 43.515 \\
\hline & & $\%$ Contorno 95 & $5 \%$ & $11 \%$ & $15 \%$ & $34 \%$ & $36 \%$ & $100 \%$ \\
\hline & & $\%$ Contorno 00 & $2 \%$ & $2 \%$ & $2 \%$ & $3 \%$ & $16 \%$ & $3 \%$ \\
\hline \multirow{2}{*}{ Total } & & Movimientos & 126.653 & 306.313 & 329.271 & 575.167 & 97.630 & 1.435 .034 \\
\hline & & $\%$ Contorno 95 & $9 \%$ & $21 \%$ & $23 \%$ & $40 \%$ & $7 \%$ & $100 \%$ \\
\hline
\end{tabular}

FUENTE CÁLCULOS DEL AUTOR CON BASE EN INEGI 2000.

el segundo destino desde el cuarto, aunque con una cifra muy similar a los destinos del interior del mismo contorno. Sin embargo, desde la ciudad central, el primer destino es el 1C, seguido de la misma ciudad central.

Desde esta perspectiva, es posible advertir que quienes dejan la ciudad central se van predominantemente al 1C (35\%), pero después les da lo mismo ir al 2C (24\%) que al 3C (25\%), a pesar de la mayor distancia al centro y costo social por el mayor tiempo de recorrido. Es importante recordar que quienes dejan la ciudad central son de más bajos ingresos que la media y lo hacen, principalmente, por un cambio de uso del suelo, de habitacional a comercial (Coulomb y Sánchez, 1991; Delgado, 1991).

Por su parte, quienes dejan el primer contorno se mueven dentro del mismo contorno (19\%) o bien se desplazan al 2C (29\%) y mayormente al 3C (38\%), siendo este último uno de los seis flujos más importantes.

El grupo de quienes dejan el $2 \mathrm{C}$ incluye básicamente a la población mexiquense de los municipios conurbados durante la expansión indiscriminada de 1950 a 1970, cuando los controles a la expansión en el DF se relajaron y las operaciones inmobiliarias especulativas tuvieron su mayor auge en el Estado de México (Iracheta, 1984). Estos habitantes se movieron mayoritariamente al 3C (50\%), es decir, se alejaron aún más de las áreas mejor servidas; no obstante, una cuarta parte se acercó al 1C, lo que puede considerarse como una mejora relativa en cuanto a localización, mientras que $16 \%$ se movió dentro del propio contorno.

Paradójicamente, el 3C, que bien puede considerarse como el contorno metropolitano más pauperizado, fue también el más dinámico. Se generó durante el periodo de 1970 a 1990, supuestamente, bajo medidas de control a la expansión, nunca totalmente efectivas 
(Eibenshutz, 2000). La mayor parte de sus nómadas metropolitanos (44\%) se cambió dentro del propio contorno y la otra mitad se acercó al $1 \mathrm{C}(17 \%)$ y al 2C (22\%), o alejándose hacia el 4C (11\%).

Por último, el cuarto contorno ha levantado mucha controversia en cuanto a su inclusión como contorno metropolitano (Connolly y Cruz, 2004), debido a que abarca una franja rural urbana aún no conurbada, pero que guarda una estrecha relación funcional con la ciudad. La mayor parte de los movimientos originados en este contorno (36\%) se quedó dentro del mismo. El resto de sus cambios fueron hacia el centro, incluyendo la ciudad central misma.

\section{Movimientos por contorno, según ingreso}

Respecto al ingreso, hemos visto que quienes cambian de residencia tienen, en promedio, un ingreso mayor al de quienes no cambiaron. Sin embargo, existe también una relación en el ingreso de las diferentes combinaciones de cambios entre contornos. Se puede decir que los movimientos que se originan en cualquiera de los contornos y que terminan en la ciudad central o el tercer contorno, tienen medias de ingreso mayores a las de quienes no cambiaron de residencia en los contornos de origen y destino. Al contrario, los que provienen del cuarto y, en algunos casos, del tercer contorno, muestran ingresos menores que los de la población que mantuvo su lugar de residencia anterior (Cuadro 8).

La ciudad central recibió a los hogares con mayor ingreso. Los hogares que salieron de la ciudad central fueron, también, los de mayor ingreso respecto a la zona metropolitana, pero de menor ingreso que los que se mudaron ahí. A medida que aumenta la distancia al centro disminuye el ingreso medio de los cambios que se originan y tienen destino en cada contorno. Hay aquí un patrón en extremo interesante. Si se compara el ingreso medio total de los cambios por contorno de origen y destino, se observa que los que llegan tienen, en promedio, mayor ingreso que los que se van. Es decir, los cambios que se originan en cada contorno representan un ingreso menor al de los cambios que tienen como destino esos mismos contornos. Aunque no se puede precisar con base en la información disponible, ello sugiere un patrón de expulsión de hogares de bajos ingresos hacia la periferia, generado por procesos de aburguesamiento (gentrification) en el

Cuadro 8 | Ciudad de México: Promedios de ingreso total del hogar de cambios residenciales entre contornos $1995-2000$

\begin{tabular}{r|ccccc|c}
\hline \multicolumn{1}{c|}{ Origen } & $\begin{array}{c}\text { CIUDAD } \\
\text { CENTRAL }\end{array}$ & $\begin{array}{c}1^{\mathrm{ER}} \\
\text { CONT. }\end{array}$ & $\begin{array}{c}2^{\mathrm{DO}} \\
\text { CONT. }\end{array}$ & $\begin{array}{c}3^{\mathrm{ER}} \\
\text { CONT. }\end{array}$ & $\begin{array}{c}4^{\mathrm{TO}} \\
\text { CONT. }\end{array}$ & TOTAL \\
\hline CIUDAD CENTRAL & 11.228 & 11.019 & 9.320 & 8.807 & 4.868 & 9.980 \\
$1^{\mathrm{ER}}$ CONTORNO & 11.663 & 8.828 & 7.708 & 5.665 & 4.385 & 7.548 \\
$2^{\mathrm{DO}}$ CONTORNO & 13.619 & 9.150 & 7.353 & 5.111 & 4.020 & 6.853 \\
$3^{\mathrm{ER}}$ CONTORNO & 12.960 & 6.795 & 6.341 & 5.868 & 4.519 & 6.490 \\
$4^{\mathrm{TO}}$ CONTORNO & 79.580 & 5.913 & 4.351 & 5.515 & 3.544 & 4.819 \\
\hline $\begin{array}{r}\text { TOTAL } \\
\text { MEDIA NO }\end{array}$ & 12.301 & 9.150 & 8.222 & 5.960 & 4.026 & 7.671 \\
CAMBIARON & 9.637 & 7.549 & 6.798 & 5.916 & 3.668 & 6.878 \\
MEDIA DEL & 9.899 & 7.679 & 6.923 & 5.925 & 3.700 & \\
CONTORNO & & & & & &
\end{tabular}

FUENTE CÁLCULOS DE LOS AUTORES CON BASE EN INEGI 2000. CONTEMPLA EL INGRESO TOTAL DE LOS HOGARES QUE TUVIERON CAMBIOS RESIDENCIALES DEL JEFE DE FAMILIA. CIFRAS EN PESOS DE 2000. 
lugar de origen, pues, en todos los casos, el destino de mayor ingreso es la ciudad central y existe una clara disminución hacia el cuarto. Por el contrario, el patrón de ingreso a partir del origen no es tan claro.

Ahora es necesario visualizar no sólo la magnitud total de los diversos cambios entre contornos, sino su proporción relativa. De no hacerlo así, se sobrestimarían los flujos provenientes de los municipios más poblados y con un mayor crecimiento poblacional absoluto. Ello es posible a través de la identificación de flujos sobresalientes.

\section{Flujos sobresalientes}

Los anteriores cambios residenciales entre contornos son relativamente fáciles de analizar, dado que sólo son cuatro contornos y una ciudad central. En cambio, los movimientos entre municipios son más difíciles de observar por medio de estadísticas básicas, pues las combinaciones posibles entre pares de municipios son más de cinco mil.

Así, para identificar los principales flujos entre pares municipales con proporciones sobresalientes de cambios residenciales, se seleccionaron, de la base de datos del censo, solamente aquellos que cumplieran las siguientes condiciones:

1) Que el número de cambios observados desde el municipio de origen excediera el número de cambios esperados desde el propio municipio.

2) Que el número de cambios observados hacia el municipio de destino excediera el número de cambios esperados hacia el mismo municipio.

3) Que la proporción de cambios per cápita desde el municipio de origen excediera la proporción media de cambios per cápita desde los municipios de origen. Es decir, que el volumen de cambios fuera suficientemente grande con relación a la población del municipio de origen.

4) Que la proporción de cambios per cápita hacia el municipio de destino excediera la proporción media de cambios per cápita hacia los municipios de destino. Es decir, que el volumen de cambios fuera suficientemente grande con relación a la población del municipio de destino.

Las restricciones anteriores se expresan de la siguiente forma:

$F_{i j}=$ Cambio Sobresaliente

Sujeto a:

$\frac{F_{i} F_{j}}{\sum F_{j}-F_{i}}<F i j, \frac{F_{i} F_{j}}{\sum F_{j}-F_{j}}<F_{j}, \frac{\sum\left(F_{j} / P o b 1995_{i}\right)}{N_{j}}<\frac{F_{j}}{P o b 1995_{i}}, y, \frac{\sum\left(F_{j} / P o b 2000_{j}\right)}{N_{j}}<\frac{F_{j}}{P o b 2000_{j}}$

$F_{i}=$ número de cambios totales que se originaron en el municipio $i$

$F_{j}=$ número de cambios totales que tuvieron como destino el municipio $j$

$F_{i j}=$ número de cambios entre el municipios de origen $i$ y el municipio de destino $j$

$\Sigma F_{i j}=$ Sumatoria de cambios residenciales entre los orígenes $i$ y los destinos $j$

Pob1995 $=$ Población en 1995 en el municipio de origen $i$

$P_{0 b 2000}=$ Población en 2000 en el municipio de destino $j$

Este cálculo asegura que los flujos seleccionados superen volúmenes y proporciones medios de cambios residenciales entre municipios, independientemente de su tamaño. Nótese que en 
el caso de las restricciones (1) y (2) existe una diferencia con el cálculo de cambios esperados si se utilizaran tablas de contingencia. Dado que no es posible conocer los cambios intramunicipales a partir de los datos del Censo, con el uso de tablas de contingencia se sobrestimaría el número de flujos observados, pues asignaría un número de flujos esperados en los municipios de la diagonal, es decir, cuando el municipio $i=j$, reduciendo el número de flujos esperados entre otros pares municipales. Por lo tanto, como los flujos observados entre municipios $i=j$ son siempre $=0$, los flujos esperados de la diagonal también deben ser $=0$. Por ello, las restricciones $(1)$ y (2) restan $F_{i}$ y $F_{j}$ de $\Sigma F_{i j}$.

Una vez identificados los flujos, se dividieron entre la categoría de ingreso del hogar, por cuartiles, para identificar las áreas de la ciudad en donde suceden los cambios residenciales. Adicionalmente, se calcularon las distancias de cambio en un ambiente SIG (GRASS v 6.01).

La metodología propuesta permite reducir en $95 \%$ (de 5.625 a 271) las combinaciones posibles de pares municipales con cambios sobresalientes. Aun así, representan $62 \%$ del total de los cambios residenciales, con una distancia media de 9,7 kilómetros entre origen y destino. Los flujos de cambios residenciales sobresalientes se muestran en la Figura 5, sobrepuestos a la migración intraurbana neta, en donde se pueden identificar cuatro comportamientos básicos:

i) Primero, la mayoría de los cambios -casi siempre líneas cortas- ocurren entre municipios contiguos.

ii) Segundo, los municipios con migración neta positiva tienen un mayor número de flujos sobresalientes entrantes que provienen de áreas con una migración positiva menor o negativa y tienen más flechas entrantes que salientes. En cambio, los municipios con migración neta negativa tienen una mayor dinámica entre ellos, con líneas entrantes desde otros municipios con migración neta negativa y una serie de líneas que terminan en municipios con migración neta positiva.

iii) En tercer lugar, además de un subsistema central principal, el mapa permite visualizar diversos subsistemas de migración intraurbana en donde se densifica el número de flujos sobresalientes. Estos subsistemas son al menos cinco: uno al Sureste, otro al Este en el área de Texcoco, dos al Norte - y quizás- , uno más al Este en el área de Iztapaluca y, finalmente, uno hacia el oriente en Santa Fe.

A reserva de profundizar en el futuro en la identificación precisa de estos subsistemas, se puede asegurar que, con excepción de Santa Fe, ninguno de los otros subsistemas fue planificado. A partir de esos primeros resultados se separaron los mapas de los diferentes niveles de ingreso - alto, medio, bajo-, de los flujos sobresalientes respectivos, para ver si tienen alguna lógica espacial precisa.

En efecto, en esta segunda serie de mapas se observa claramente que el ingreso medio per cápita en el hogar es alto en los flujos sobresalientes. Estos flujos se concentran en el área del Distrito Federal y comienzan a mezclarse con flujos sobresalientes de otras categorías, de Sur a Norte y de Oeste a Este. En contraste, los flujos sobresalientes de ingresos medio-bajo y bajo se agrupan hacia la periferia, en las áreas urbanas no continuas al Norte, Este y Sureste de la ciudad. Por su parte, los flujos de ingreso medio-alto se presentan más hacia las orillas del D.F, hacia el Norte y al Este en el tercer contorno metropolitano. La mayoría de los cambios de ingreso alto sucedieron entre municipios con cambios en el ingreso per cápita municipal por encima de la media metropolitana, y los de bajo ingreso en los municipios con cambios en el ingreso por debajo de la media (Figura 6). 
FIGURA 5 | Cambios residenciales sobresalientes y migración intraurbana neta 1995-2000

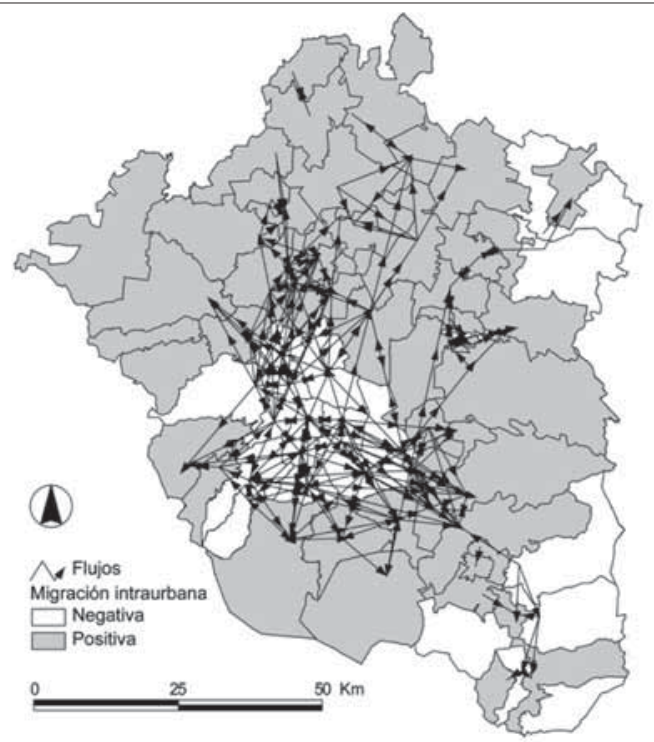

FUENTE ELABORACIÓN PROPIA A PARTIR DE CÁLCULOS CON BASE EN INEGI, 2000.

FIGURA 6 | Cambios residenciales sobresalientes por categoría de ingreso 1995-2000 y cambio en el ingreso municipal respecto al cambio metropolitano, 1990-2000

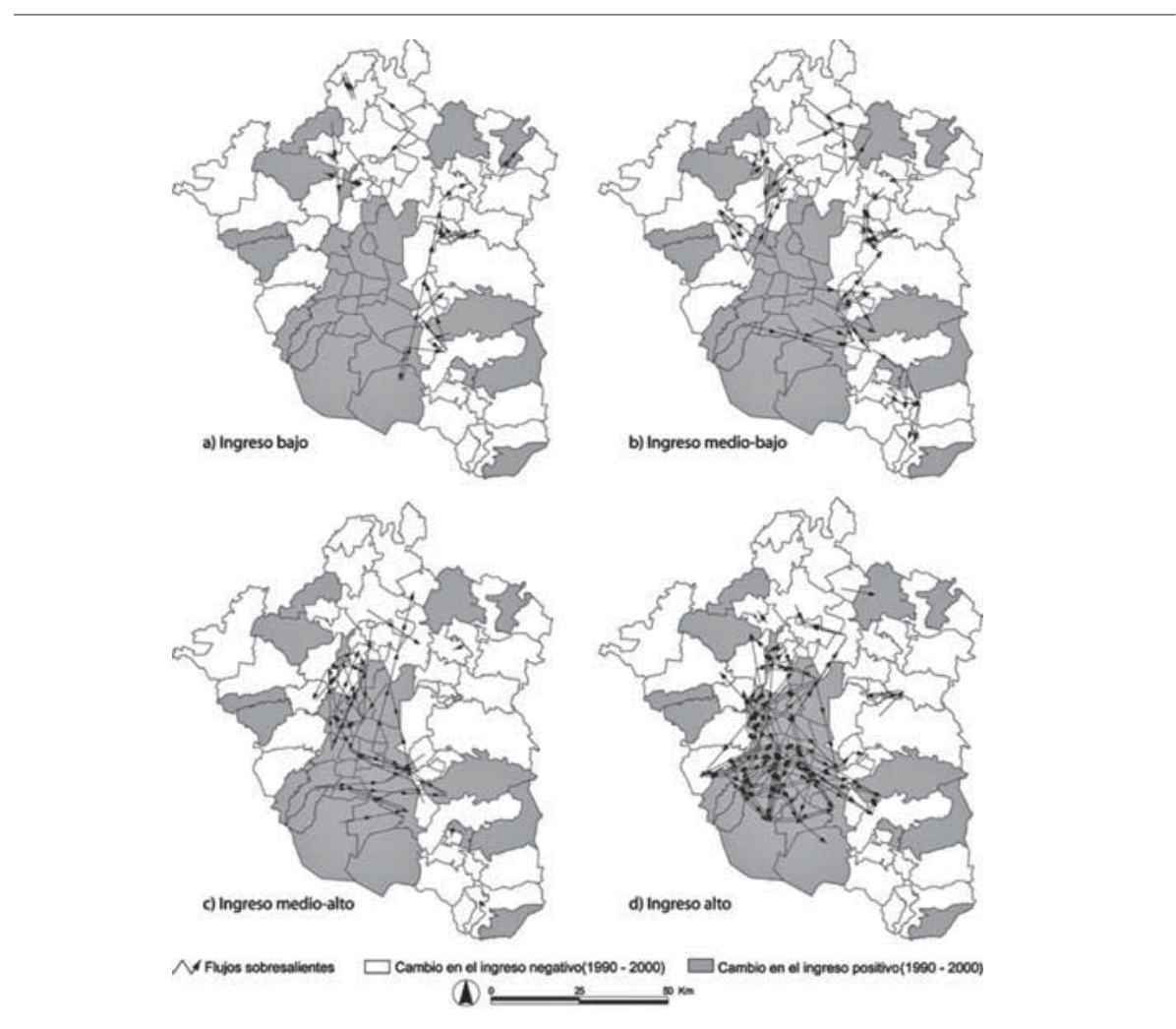

FUENTE ELABORACIÓN PROPIA A PARTIR DE CÁLCULOS CON BASE EN INEGI, 2000. 
En síntesis, se puede suponer al ingreso como la variable idónea para explicar la correlación espacial entre el impulso y atracción de los diferentes pares de municipios con flujos sobresalientes. Falta ver ahora si los flujos descritos están sujetos sólo a la dinámica poblacional en el sitio de origen y destino o si hay una serie de variables que permitan identificar un probable patrón de co-localización entre empleos y vivienda.

\section{Cambios residenciales municipales y volumen de flujos de trabajo}

En el análisis anterior se identificó la espacialidad de los cambios residenciales entre pares municipales y su relación con el ingreso. Asimismo, se identificaron pares de municipios con cambios residenciales sobresalientes calculados a partir de proporciones esperadas de flujos y no por su volumen.

Ese procedimiento es necesario, pues de lo contrario se obtendrían como flujos sobresalientes los que suceden entre los municipios más poblados y entre los municipios con un mayor crecimiento poblacional absoluto. Visto así, conviene preguntarse si, en efecto, el volumen de los flujos está sujeto únicamente a la dinámica poblacional local. Es decir, si el volumen de población y el cambio poblacional por municipio explican por completo los flujos entre ellas. De ser así, el aumento en la oferta de vivienda junto con la proporción de crecimiento poblacional deberían explicar el volumen total de los cambios residenciales entre pares de municipios. La hipótesis alternativa que aquí se plantea es que existe una serie de variables socioeconómicas que explican el volumen de flujos entre pares municipales y que permiten identificar un patrón de co-localización entre empleos y vivienda.

Utilizando variables de población y vivienda como variables de control, y a partir de la base de datos de la Muestra Censal, se corrió un modelo de regresión lineal, log-log. En este caso, la variable dependiente es el número de cambios residenciales de jefes de familia entre pares de municipios y delegaciones, tomados de una muestra de $n=778$ pares municipales. Este número se determinó por la disponibilidad de información de todas las variables empleadas en el modelo. La matriz de cambios residenciales fue construida identificando a aquellos jefes de familia cuyo municipio de residencia en 2000 fuera distinto al de 1995. A partir de esa clasificación se agregaron los casos para cada uno de los pares municipales en la Muestra. Además de las variables de control, se incluyó información, tanto del origen como del destino, sobre cambios en el ingreso de la población, crecimiento de empleos y cambios en la proporción de vivienda en renta.

Para identificar si, en efecto, existen indicios de co-localización, se incluyó una variable de flujos de trabajo entre municipios a partir de la Encuesta Origen Destino de 1994 (EOD94). Es necesario recalcar que, al comparar el coeficiente correlación entre los cambios residenciales y los flujos de trabajo, tanto de la EOD94 $(r=0,63)$ como del censo mismo $(r=0,51)$, la primera resultó ser significativamente más alta. Esos viajes de trabajo aproximan los flujos cotidianos que ocurrían justo antes de que se comenzaran a realizar los cambios residenciales detectados en la Muestra Censal, lo que sugiere un primer indicio de co-localización.

Adicionalmente, se incluyó como variable predictiva el cambio en el índice de accesibilidad a empleos ajustado por ocupación entre 1990 y 2000 que, para un año dado, se calcula mediante:

$$
A_{i}=\sum_{i} \sum_{j}\left[p_{i k} \cdot E_{j k}\right] \cdot D_{i j}^{-1}
$$


donde:

$\mathrm{A}_{i}=$ Índice de accesibilidad a empleos en el municipio $i$

$\mathrm{E}_{j k}=$ Número de empleos en el sector de ocupación $k$ en el centro de empleo $j$.

$\mathrm{P}_{i k}=$ Número de residentes empleados en la zona $i$ en el sector de ocupación $k$.

$\mathrm{D}_{i j}=$ Distancia mediante la red de transporte entre las zonas $i \mathrm{y} j$.

$\lambda=$ Coeficiente de impedancia calculado empíricamente como -0,82

$\mathrm{k}=$ Sectores de ocupación donde $\mathrm{k}=[1 \ldots 11]$. (1) Minería, (2) Manufacturas, (3)

Electricidad y agua, (4) Construcción, (5) Comercio, (6) Transporte, (7) Sector financiero y bienes inmuebles, (8) Servicios profesionales y técnicos, (9) Servicios sociales y de salud,(10) Servicios personales y (11) Servicios de restaurantes y hoteles.

Los resultados del análisis de regresión explican 79\% de la variación del volumen de flujos entre pares municipales metropolitanos (Cuadro 9). Todas las variables se transformaron a logaritmos naturales, por lo cual los coeficientes deben interpretarse como elasticidades.

El mayor peso explicativo está en las variables de población ${ }^{6}$. Dado que actúan como variables de control, en efecto, se esperaría que los flujos entre origen y destino disminuyan a medida que la velocidad de crecimiento poblacional en el municipio de origen es mayor y que, cuando esa variable aumente en el destino, los flujos entre origen y destino también aumenten.

CUADRO 9 | Regresión: Número de cambios residenciales entre pares de municipios y delegaciones 1995-2000

\begin{tabular}{|c|c|c|c|c|c|}
\hline & \multicolumn{2}{|c|}{ Coeficientes } & \multirow{2}{*}{$\frac{\text { Coef. Estandar }}{\text { Beta }}$} & \multirow{2}{*}{$\mathrm{T}$} & \multirow{2}{*}{ Sig. } \\
\hline & B & Error Estándar & & & \\
\hline (Constante) & $-2,55$ & 0,92 & & $-2,78$ & 0,01 \\
\hline Flujos de trabajo O-D 1994 & 0,40 & 0,03 & 0,42 & 13,3 & 0,00 \\
\hline $\begin{array}{l}\text { \% de cambio en el número de } \\
\text { viviendas 95-00 (destino) }\end{array}$ & 0,07 & 0,03 & 0,08 & 2,65 & 0,01 \\
\hline $\begin{array}{l}\text { Cambio proporcional de viviendas } \\
\text { rentadas } 95-00 \text { (origen) }\end{array}$ & $-0,40$ & 0,21 & $-0,05$ & $-1,92$ & 0,06 \\
\hline $\begin{array}{l}\text { Cambio proporcional de viviendas } \\
\text { rentadas } 95-00 \text { (destino) }\end{array}$ & 0,87 & 0,24 & 0,11 & 3,63 & 0,00 \\
\hline $\begin{array}{l}\text { Cambio en el ingreso en relación a } \\
\text { la ZMCM 95-00 (origen) }\end{array}$ & 1,40 & 0,18 & 0,18 & 7,98 & 0,00 \\
\hline $\begin{array}{l}\text { Cambio en el ingreso en relación a } \\
\text { la ZMCM 95-00 (destino) }\end{array}$ & $-0,54$ & 0,19 & $-0,07$ & $-2,90$ & 0,00 \\
\hline $\begin{array}{l}\text { Cambio en la accesibilidad a } \\
\text { empleos 90-00 (origen) }\end{array}$ & $-0,28$ & 0,10 & $-0,09$ & $-2,77$ & 0,01 \\
\hline $\begin{array}{l}\text { Cambio proporcional de empleos } \\
94-99 \text { (origen) }\end{array}$ & 1,44 & 0,86 & 0,44 & 1,68 & 0,09 \\
\hline $\begin{array}{l}\text { Cambio proporcional de empleos } \\
94-99 \text { (destino) }\end{array}$ & $-1,72$ & 0,90 & $-0,45$ & $-1,91$ & 0,06 \\
\hline $\begin{array}{l}\text { Velocidad de crecimiento } \\
\text { poblacional en relación a la ZMCM } \\
95-00 \text { (origen) }\end{array}$ & $-1,20$ & 0,68 & $-0,47$ & $-1,77$ & 0,08 \\
\hline $\begin{array}{l}\text { Velocidad de crecimiento } \\
\text { poblacional en relación a la ZMCM } \\
95-00(\text { destino) }\end{array}$ & 1,55 & 0,69 & 0,54 & 2,25 & 0,03 \\
\hline Distancia entre municipios & $-0,81$ & 0,07 & $-0,29$ & $-11,7$ & 0,00 \\
\hline Población 1995 (origen) & 1,34 & 0,38 & 0,85 & 3,54 & 0,00 \\
\hline Población 2000 (origen) & $-0,78$ & 0,39 & $-0,47$ & $-2,01$ & 0,05 \\
\hline Población 2000 (destino) & 3,47 & 0,48 & 1,85 & 7,18 & 0,00 \\
\hline Población 1995 (destino) & $-2,98$ & 0,47 & $-1,69$ & $-6,41$ & 0,00 \\
\hline \multicolumn{6}{|l|}{ a Todas las variables en forma de logaritmo natural } \\
\hline Cuadrada Ajustada $=0.79$ & Sig. $=0.000$ & $\mathrm{~N}=778$ & & & \\
\hline
\end{tabular}

FUENTE CÁLCULOS DEL AUTOR CON INFORMACIÓN DE INEGI, 2000; 1999, I995; 1994; Y SETRAVI, I994.

6 Hacemos hincapié en que los casos del modelo son pares municipales y que la variable dependiente son flujos unidireccionales entre municipios de orígen y destino, por lo que no es posible una correlación mecánica con las variables de control y que, además, se expresan como cambios relativos. El propósito del modelo es demostrar que los flujos residenciales entre municipios dependen no sólo de la dinámica poblacional. 
Las variables que siguen, en cuanto a poder explicativo, son los cambios proporcionales de empleo con relación al periodo anterior. De acuerdo con los coeficientes obtenidos, un aumento de $10 \%$ en la proporción de empleos en el origen genera un aumento de $14 \%(B=1,44)$ en los cambios residenciales entre pares de municipios, lo que significa que el aumento de empleos es un factor de expulsión de residentes controlando para el resto de las variables en el modelo. A su vez, un aumento de $10 \%$ en la proporción de empleos en el destino reduce el número de flujos en $17 \%(B=-1,72)$ (Cuadro 9).

Todo esto revela una lógica de valorización del suelo impulsada por la generación de empleos que requiere un mayor consumo de suelo urbano. Lo que resulta particularmente interesante es que los flujos de trabajo entre municipios están altamente correlacionados con los flujos residenciales. El modelo incluye los flujos de trabajo entre pares municipales de la EOD94, cuyo coeficiente de correlación $(\mathrm{r}=0,63)$ resultó ser más alto que el de los flujos de trabajo del Censo 2000 ( $r=0,51$ ). Esta diferencia en la correlación podría sugerir que una parte de los viajes al trabajo entre pares municipales fueron minimizados realizando cambios de residencia entre esos mismos pares de municipios, pero sólo si suponemos que el lugar de empleo es el mismo antes y después del cambio residencial, lo cual no es posible saber a partir de los datos del censo.

El poder explicativo de esa variable (Beta) es similar a las variables de población y de empleo. De acuerdo con su coeficiente, un incremento de $10 \%$ en los flujos de trabajo al principio del periodo genera $4 \%$ de aumento en los flujos de cambio residencial. A pesar de la agregación a nivel de par municipal, el comportamiento de esta variable sugiere que al menos una parte de quienes cambian de residencia lo hacen para estar más cerca de las fuentes de trabajo, lo que constituye un proceso de co-localización.

Con menor poder explicativo, pero altamente intuitivas, están las variables de cambio de ingreso. Si el cambio en el ingreso (con relación al promedio metropolitano) aumenta en el origen, el municipio tenderá a expulsar más personas. Por el contrario, si aumenta en el destino, el municipio tenderá a atraer menos cambios. Esta variable puede estar relacionada con los cambios en la renta del suelo y con procesos de aburguesamiento (gentrification), en el sentido "cultural" como han sugerido Duhau (2003) y Schteingart y Rubalcava (2000).

Como es de esperarse, un aumento en el número de viviendas en el destino está correlacionado con un mayor número de flujos, es decir, funciona como un factor de atracción (en el sentido de artefacto). Al mismo tiempo, a medida que aumenta la proporción de viviendas rentadas en el destino, los cambios también aumentan, mientras que una mayor proporción de viviendas rentadas en el origen reduce el número de cambios hacia otros municipios.

Finalmente, el cambio en la accesibilidad a empleos en el origen disminuye el número de flujos, es decir, retrae la expulsión de emigrantes. Esto fortalece la interpretación de la variable "flujos de trabajo" pues, en igualdad de circunstancias, a medida que existen más empleos apropiados para los residentes de un municipio, es menor su expulsión hacia otras zonas de la ciudad.

En resumen, el modelo obtenido muestra que la movilidad intraurbana no está determinada, únicamente, por la dinámica poblacional o por la oferta de vivienda. La relación entre la localización del empleo, el sector de actividad económica de los residentes y la accesibilidad a los mercados de trabajo son factores importantes en localización residencial, aunque ninguno es por sí mismo determinante. 
Todavía falta saber si existe un segundo tipo de asociación entre la localización del empleo y la vivienda. En la siguiente sección se aborda la decisión de cambiar de lugar de empleo en función del cambio en la localización de la vivienda, cuando este cambio implica un distanciamiento del trabajo y un aumento en el tiempo de recorrido.

\section{Cambio de trabajo en función del cambio de residencia}

Hay un límite racional del distanciamiento del trabajo (Simpson, 1992; Clark et al., 2003). A menos que se trate de empleos que no requieren de una localización específica (que si existen deben ser muy pocos), el tiempo de recorrido al trabajo debe ocupar sólo una determinada proporción del tiempo disponible por las personas, pues, si no, las ciudades simplemente no existirían.

Ello lleva a preguntarse equé tan lejos del trabajo está dispuesta a mudarse una persona, sin antes considerar también cambiar de lugar de empleo? En nuestro caso, un tercio de las personas encuestadas, junto con el cambio de residencia, reportaron haber cambiado de lugar de ocupación. Dado que en la encuesta propia se preguntó por la localización de vivienda y trabajo, anteriores y actuales, es posible saber cuál hubiese sido la distancia de recorrido al trabajo si sólo se hubiese cambiado de lugar de residencia.

Para identificar si tal asociación existe, se recurrió a un modelo logístico binomial para estimar la probabilidad de que un jefe de familia que cambió de residencia cambiara también de lugar de trabajo, con datos de la encuesta propia. La variable dependiente se codificó como 1 -cuando existió un cambio de lugar de trabajo-, y como 0 -cuando el lugar de trabajo permaneció igual en el lugar de vivienda anterior y el actual-.

Las variables predictivas se seleccionaron con base en la teoría. En este caso, la variable predictiva de interés es la distancia entre la vivienda actual y el trabajo anterior, que daría indicios de co-localización cuando el coeficiente es positivo. En efecto, de acuerdo con los supuestos clásicos de localización, la co-localización se presenta cuando, a medida que aumenta la distancia entre el nuevo hogar y el viejo trabajo (que impulsó el cambio residencial), también incrementa la probabilidad de cambiar de trabajo.

El resto de las variables utilizadas en el modelo incluyen el incremento de sueldo antes y después de cambiar de residencia $(0=\mathrm{NO}, 1=\mathrm{SI})$, la disponibilidad de automóvil $(0=\mathrm{NO}$, $1=\mathrm{SI}$ ) y el motivo de cambio clasificado como voluntario (compra-venta, relacionado al trabajo, mejora de la vivienda, matrimonio e independencia) e involuntario (desalojo, problemas económicos, inseguridad, problemas con vecinos, medio ambiente).

El modelo predice correctamente $77 \%$ de los casos y tiene un poder explicativo de $39 \%$, de acuerdo con la R cuadrada de Nagelkerke, lo que lo hace un modelo altamente satisfactorio 7 . El uso del automóvil disminuye en $77 \%$ las probabilidades de cambio de trabajo [ $\operatorname{Exp}(B)]$, es decir, permite continuar en el mismo trabajo, aunque aumente la distancia al mismo dado un cambio de residencia. Por su parte, el aumento en el sueldo incrementa nueve veces las posibilidades de cambio (Cuadro 10).

El modelo muestra que, cuando el cambio residencial es voluntario, existe una mayor probabilidad de cambio de trabajo. Esto quizá se deba a que los cambios voluntarios son planeados, por lo que es posible realizar cambios conjuntos de residencia y trabajo. Finalmente, al comparar la distancia entre la vivienda actual y el trabajo que se tenía en la localización anterior, resulta que a mayor distancia aumenta también la probabilidad de cambio a un nuevo empleo. El modelo muestra que, cuando el cambio residencial genera una desutilidad suficiente por el incremento en la distancia al trabajo, las personas tenderán a buscar un nuevo trabajo pero, ahora, con relación a la nueva localización residencial. En nuestra opinión, esta es una evidencia clara de la existencia de co-localización.

7 Se consideran análisis logísticos con poder explicativo aceptables cuando muestran una R cuadrada de Nagelkerke de 0,20. Véase Tabachinik y Fidell, 2000. 
CUADRo 10 | Regresión logística: Probabilidad de cambio de lugar de trabajo entre localizaciones de vivienda anterior y actual (Jefes de familia)*

\begin{tabular}{lccccc}
\hline \multicolumn{1}{c}{ Variables } & Coeficiente & Error estándar & Wald & Sig. & Exp(B) \\
\hline $\begin{array}{l}\text { Logaritmo de la distancia } \\
\text { entre la vivienda actual y }\end{array}$ & 0,4 & 1,78 & 5,0 & 0,03 & 1,49 \\
$\begin{array}{l}\text { el trabajo anterior } \\
\text { Incremento del sueldo }\end{array}$ & 2,2 & 0,18 & & & \\
Automóvil & $-1,47$ & 0,46 & 8,4 & 0,00 & 0,23 \\
Cambio voluntario & 1,02 & 0,51 & 3,9 & 0,05 & 2,76 \\
Constante & $-5,95$ & 0,52 & 11,2 & 0,00 & 0,00 \\
\hline
\end{tabular}

R2 de Nagelkerke $=0,39$

Chi Cuadrada $=54$. Sig. $=0,000$

Casos correctamente clasificados: cambio de lugar de trabajo: No=79\%; $\mathrm{Si}=73 \%$, Total $=77 \%$

*Adicionalmente, se corrió un modelo alternativo "completo" que incluía como variables predictivas el ingreso del hogar y el cambio en la distancia de recorrido si no se hubiese cambiado de lugar de trabajo. Ninguna resultó significativa y aportaban poco al modelo. Utilizando el Criterio de información de Akaike, se eligió el modelo que se presenta, cuyo valor de dicho estadístico resultó más bajo.

FUENTE CÁLCULOS A PARTIR DE LA ENCUESTA DEL AUTOR.

\section{Conclusiones}

Los propósitos de este artículo han sido, primero, describir las generalidades del proceso de movilidad residencial y, segundo, observar la relación entre la elección de localización residencial y el lugar de trabajo como variables dinámicas, ambas intrínsecamente relacionadas con los cambios a la estructura urbana.

La dinámica de los cambios residenciales es, por demás, compleja. Las estadísticas presentadas muestran que el ingreso, la tenencia de renta, el cambio de lugar de trabajo o el deseo de contar con una vivienda propia se relacionan con la probabilidad de cambio residencial. A la vez, existen factores que restringen la movilidad como son la edad, el tamaño del hogar y la tenencia de vivienda propia. El análisis sugiere una serie de movimientos residenciales, por lo general concéntricos, tanto en volumen de flujos residenciales como en términos del ingreso.

Los cambios residenciales, por lo general, involucran distancias relativamente cortas y la mayoría de los flujos sobresalientes ocurren entre unos cuantos municipios que, además, son los más poblados. Sin embargo, ese volumen de flujos no está en función, únicamente, de la disponibilidad de vivienda y las dinámicas poblacionales, sino del volumen de flujos de trabajo entre pares de municipios en el periodo inicial del cambio residencial. Ello significa que la fuerza que dirige el cambio residencial está en función de la accesibilidad a empleos, ya sea generada por el cambio residencial en el municipio de destino o por el cambio en la estructura del empleo en el municipio de origen. Esto indica que la movilidad residencial es parte importante de un proceso de co-localización entre los empleos y viviendas, lo que lo convierte en un mecanismo social de equilibrio de la estructura urbana o, como se ha sugerido aquí, lo hace operar como un artefacto cultural único.

Una limitación del análisis realizado es el nivel de agregación por par municipal, es decir, que el mismo análisis por AGEB daría una pauta precisa de los efectos espaciales de los procesos analizados. Sin embargo, con el último modelo presentado no se corre el riesgo de caer en una falacia ecológica, pues se realiza a nivel de personas. En este último análisis se probó que la localización residencial y el lugar de trabajo están intrínsecamente relacionados. En efecto, la cercanía al trabajo representa la segunda causa de movilidad residencial. Aun cuando no suceda por esta causa, la información presentada 
sugiere que si la distancia al trabajo aumenta, el cambio residencial tiende a minimizar el aumento en el recorrido al trabajo. Cuando esto no ocurre, se opta también por un cambio de lugar de trabajo que reduzca el aumento en el recorrido.

Al final, la cuestión de fondo del problema sigue siendo el vacío institucional que el modelo neoliberal ha dejado en nuestro entramado social, económico y político, largamente construido. Como se ha mostrado aquí, hay una clara expulsión de pobladores de bajos ingresos hacia la periferia y una concentración de los ingresos más altos en el centro de la metrópolis. Los subsistemas espaciales de movilidad resultantes parecen obedecer más al mercado que a la planeación, a pesar de que sabemos que el aumento del empleo en un determinado sitio es un factor de expulsión de los residentes más pobres.

La planeación institucional de nuevos centros de empleo podría decidirse al lado de políticas específicas de vivienda, según el ingreso y garantizar la accesibilidad urbana a través de transporte público. Para ello, hace falta Estado. IEURE

\section{Referencias bibliográficas}

Aguilar, A. G. \& Alvarado, C. (2005). La reestructuración del espacio urbano de la Ciudad de México. ¿Hacia la metrópoli multinodal? En A. G. Aguilar (Ed.). Procesos metropolitanos grandes ciudades. Dinámicas recientes en México y otros paises (pp. 265-308). México: Porrúa.

Alonso, W. (1964). Location and Land Use. Boston: MIT PRESS.

Bogart, W. T. (1998). The economics of cities and suburbs. Upper Saddle River, N.J.: Prentice Hall.

Brown, L. A. \& Moore, E. G. (1970). The Intra-Urban Migration Process: A Perspective. Geografiska Annaler-B, 52, 1-13.

Cervero, R. \& Wu, K.-L. (1997). Polycentrism, commuting, and residential location in the San Francisco Bay Area. Environment and Planning A, 29, 865-886.

Cervero, R. \& Wu, K.-L. (1998). Subcentering and commuting: evidence from the San Francisco Bay Area, 1980-1990. Urban Studies, 35(7), 1059-1076.

Chinitz, B. (1961). Contrasts in Agglomeration. Papers and Proceedings of the American Economic Association, 279:289.

Clark, W. A. V., Huang, Y. \& Withers, S. (2003). Does Commuting Distance Matter? Commuting Tolerance and Residential Change. Regional Science and Urban Economics, 33 199-221.

Connolly, P. \& Cruz, M. S. (2004). Nuevos y viejos procesos en la periferia de la Ciudad de México. En A. G. Aguilar (Ed.). Procesos metropolitanos y grandes ciudades. Dinámicas recientes en México y otros países. México: Instituto de Geografía, CRIM, CONACyT y Porrúa.

Coulomb, R. \& Mejorada, C. S. (1991). ¿Todos propietarios? Vivienda de alquiler y sectores populares en la Ciudad de México. México: Centro de la Vivienda y Estudios Urbanos.

Cronin, F. J. (1979). Low-Income Household's Search for Housing: Preliminary Findings on Racial Differences. Washington, D.C.: Urban Institute.

Cruz Rodríguez, L. \& Duhau, E. (2001). Los procesos de urbanización periférica y la relación entre vivienda y empleo en la zona metropolitana de la Ciudad de México. En E. Duhau (Ed.). Procesos Metropolitanos (pp. 123-153). México: RIU-UAM-A.

De Mattos, C. A. \& Hidalgo Fortunatti, R. (2007). Santiago de Chile: movilidad espacial y reconfiguración metropolitana. Santiago, Chile: Instituto de Estudios Urbanos y Territoriales Instituto de Geografía, Pontificia Universidad Católica de Chile.

Deitz, R. (1998). A Joint Model of Residential and Employment Location in Urban Areas. Journal of Urban Economics, 44 (Issue 2), 197-215.

Delaunay, D. \& Dureau, F. (2004). Componentes sociales y espaciales de la movilidad residencial en Bogotá. Estudios Demográficos y Urbanos, 19 (1), 77-113.

Delgado, J. (1988). El patrón de ocupación territorial de la Ciudad de México al año 2000. En O. Terrazas y E. Preciat (Eds.). Estructura Territorial de la Ciudad de México. México: Plaza y Valdez. 
Delgado, J. (1991). Centro y periferia en la estructura socioespacial de la Ciudad de México. En M. Schteingart (Ed.). Espacio y vivienda en la Ciudad de México (pp. 85-105). México: El Colegio de México I Asamblea de Representantes del Distrito Federal.

Delgado, J., Ramírez, P., Salgado, M. \& Camarena, M. (1997). Estructura Urbana y Transporte. En R. Eibenschutz (Ed.). Bases para la planeación del Desarrollo Urbano en la Ciudad de México (Vol. II, pp. 7-67.). México: UAMPorrúa.

Eibenschutz, R. \& Rébora, A. (2000). El desarrollo urbano del Distrito Federal en el año 2000. México: Secretaría de Desarrollo Urbano, Gobierno del Distrito Federal.

Fujita, M. (1999). Urban Economic Theory. Cambridge: Cambridge University Press.

García Lascurain, M. (1991). Calidad de vida en el trayecto a la periferia metropolitana. En J. Delgado y D. R. Villareal (Eds.). Cambios territoriales en México. Exploraciones recientes. México: UAM-X. GDF (2007). Encuesta Origen Destino.

Graizbord, B. (2008). Geografía del transporte en el área metropolitana de la Ciudad de México. México: El Colegio de México.

Graizbord, B. \& Acuña, B. (2005). La estructura polinuclear del Área Metropolitana. En A. G. Aguilar (Ed.). Procesos metropolitanos y grandes ciudades. Dinámicas recientes en México y otros países (pp. 309-328). México: Porrúa.

Graizbord, B. \& Santillán, M. (2005). Dinámica demográfica y generación de viajes al trabajo en el AMCM: 1994-2000. Estudios Demográficos y Urbanos, 20(1), 71-101.

Graizbord, B. \& Acuña, B. (2007). Movilidad residencial en la Ciudad de México. Estudios Demográficos y Urbanos, 22 (2), 291-335.

Hamilton, B. (1982). Wasteful Commuting. Journal of Political Economy (90), 1035-1053.

Hanushek, E. A. \& Quigley, J. M. (1978). An Explicit Model of Intra-Metropolitan Mobility. Land Economics, 54, 411-429.

Huff, J. O. \& Clark, W. A. V. (1978). Cummulative Stress and Cummulative Inertia: A Behavioral Model of the Decision to Move. Environment and Planning, 10(1101-1119).

INEGI (1995). Base de Datos del I Conteo de Población y Vivienda 1995. Aguascalientes, México: Instituto Nacional de Estadística Geografía e Informática.

INEGI (1999) Censos económicos 1999. Aguascalientes, México: Instituto Nacional de estadística Geografía e Informática.

INEGI (2000) XII Censo de población y vivienda 2000. Base de datos de la muestra censal, Aguascalientes, México.

INEGI (2010) Estadísticas vitales 1990-2003. México: Instituto Nacional de Estadística Geografía e Informática. Disponible en [http://sc.inegi.org.mx/simbad/].

Iracheta, A. (1984). El suelo urbano, recurso estratégico para el desarrollo urbano. Toluca, México: División de Estudios de Posgrado de la Facultad de Arquitectura y Arte, Universidad Autónoma del Estado de México.

Kaldor, N. (1985). Economics without equilibrium: ME Sharpe, Inc. Cardiff: University College of Cardiff Press.

Krugman, P. R. (1991). Geography and trade. Leuven, Belgium Cambridge, Mass: Leuven University Press; MIT Press.

Levinson, D. \& Kumar, A. (1994 ). The Rational Locator: Why Travel Times Have Remained Stable. Journal of the American Planning Association, $60319-332$.

Mills, E. S. (1972). Studies in the structure of the urban economy. Baltimore: The Johns Hopkins Press.

Muth, R. (1969). Cities and Housing. Chicago: University of Chicago Press.

Pinto da Cunha, J. M. (2002). Urbanización, redistribución espacial de la población y transformaciones socioeconómicas en América Latina. Santiago de Chile: Comisión Económica para América Latina.

Programa (1996). Programa de Ordenación de la Zona Metropolitana del Valle de México. México: Sedesol, Gobierno del Estado de México y Gobierno del Distrito Federal.

Quigley, J. M. (1977). Intra-Urban Residential Mobility: A Review and Synthesis. International Regional Science Review, 2 (Fall), 41-66. 
Rubalcava, R. M. \& Schteingart, M. (1987). Estructura urbana y diferenciación socioespacial en la zona metropolitana de la Ciudad de México (1970-80). En G. Garza (Ed.). Atlas de la Ciudad de México. México: Departamento del Distrito Federal, El Colegio de México.

Schteingart, M. \& Graizbord, B. (1998). Vivienda y vida urbana en la Ciudad de México: la acción del Infonavit. México: Centro de Estudios Demográficos y de Desarrollo Urbano, El Colegio de México.

Schteingart, M. \& Ruvalcaba, R. M. (2000). Segregación Socioespacial. En G. Garza (Ed.). La Ciudad de México en el fin del segundo milenio (pp. 287-294). México: El Colegio de México, Gobierno del Distrito Federal.

SEDESOL (2000). Programa de Ordenación de la Zona Metropolitana del Valle de México. México, Secretaría de Desarrollo Social.

SETRAVI (1994). Encuesta origen destino de la Ciudad de México 1994. México: Secretaría de Transporte y Vialidad y Gobierno del Distrito Federal.

Simpson, W. (1992). Urban Structure and the Labour Market: Worker Mobility, Commuting, and Underemployment in Cities. Oxford: Clarendon Press.

Smith, T. R., Clark, W. A. V., Huff, J. O., \& Shapiro, P. (1979). A Decision Making and Search Model for Interurban Migration. Geographical Analysis, 11, 1-22.

Sobrino, J. (2007) Patrones de dispersión intrametropolitana en México. Estudios Demográficos y Urbanos, 22 (7): 583-617

Sobrino, J. (2008). Movilidad intrametropolitana en la Ciudad de México. Estudios Demográficos y Urbanos, 22 (7): 583-617.

Sobrino, L. J. \& Ibarra, V. (2005). Movilidad intrametropolitana en la Ciudad de México. Trabajo no publicado. El Colegio de México.

Suárez, M. (2007). Mercados de trabajo y localización residencial en la ZMCM. Tesis doctoral no publicada, México D.F: Universidad Nacional Autónoma de México.

Suárez, M. \& Delgado, J. (2009). Is Mexico City Polycentric? A trip attraction capacity approach. Urban Studies.

Weinberg, D. H., Friedman, J. \& May, S. K. (1981). Intraurban Residential Mobility: The Role of Transaction Costs, Market Imperfection, and Household Desequilibrium. Journal of Urban Economics, 9, 332-348. 